\title{
Taxonomy of Guatemalan water beetles in the genus Hydrochus (Coleoptera: Hydrochidae)
}

\author{
Philip D. PERKINS \\ Department of Entomology, Museum of Comparative Zoology, Harvard University, Cambridge, MA 02138 USA; \\ e-mail: perkins@oeb.harvard.edu
}

\author{
Accepted: \\ $17^{\text {th }}$ April 2020 \\ Published online: \\ $23^{\text {rd }}$ April 2020
}

\begin{abstract}
The taxonomy of Guatemalan water beetles in the genus Hydrochus Leach, 1817 (Coleoptera: Hydrophiloidea: Hydrochidae) is presented. The known fauna now consists of six species, four of which are described as new species. The new species are diagnosed, and high -resolution images of the habitus and male genitalia of each species are given. The following new species are described: $H$. directus sp. nov., $H$. pertuberculatus sp. nov., $H$. sinuatus sp. nov., and H. steineri sp. nov. The historical types of H. debilis Sharp, 1882 and H. obscurus Sharp, 1882 are redescribed, their lectotypes are designated, and high-resolution images of the habitus, male genitalia and labels of the lectotypes are given.
\end{abstract}

Key words. Coleoptera, Hydrophiloidea, Hydrochidae, Hydrochus, new species, lectotype designation, Guatemala, Central America, Neotropical Region

Zoobank: http://zoobank.org/urn:1sid:zoobank.org:pub:45563A23-8582-4C53-81F3-591948E7A74D

(C) 2020 The Authors. This work is licensed under the Creative Commons Attribution-NonCommercial-NoDerivs 3.0 Licence.

\section{Introduction}

The American members of the genus Hydrochus Leach, 1817 have had a very troubled history including, among other issues, the frequently inaccurate and consequently unreliable work of MAKHAN (1992, 1993, 1994, 1995a,b, 1996, 1998, 2000, 2001, 2004a,b, 2005). Because of the inadequate descriptions together with the generalized and inaccurate male genitalia illustrations, it is necessary to borrow all types whenever revisionary studies are done. The taxonomic and nomenclatural problems caused by D. Makhan are comprehensively discussed in Oliva (2000), JÄCH (2006), SHORT \& HEBAUER (2006) and WorTHINGTON et al. (2016). Additional taxonomic difficulties result from the inaccurate male genitalia illustrations of Neotropical Hydrochus by Oliva $(1992,1996)$ (for details see PerKINS 2019a,b). Although neither D. Makhan nor A. Oliva described new species from Guatemala, it is necessary to be informed about all species of Hydrochus described from the Neotropical Region, before describing any new species, because distributions in the genus are sometimes wide. Discussion of relationships of the Guatemalan fauna is not possible until revisionary studies are done on other Central American countries, which are in progress.
Here, knowledge of the Hydrochus fauna of Guatemala is improved, based on the examination and study of specimens in the collections of the Smithsonian Institution, Washington D.C., USA and Natural History Museum in London, UK, and examination of many type species of previously described Neotropical species. The known fauna now consists of six species, four of which are described as new species. The following new species are described: $H$. directus, $H$. pertuberculatus, $H$. sinuatus, and $H$. steineri. The historical types of species described in Biologia Centrali-Americana by SHARP (1882), H. obscurus Sharp, 1882 and $H$. debilis Sharp, 1882, are redescribed, lectotypes are designated, and high-resolution images of the habitus and male genitalia of the lectotypes are given, as are images of the pin labels of the lectotype specimens. High resolution images of the habitus and male genitalia of the four new species are also provided.

\section{Material and methods}

The materials and methods used for specimen preparation and specimen imaging follow those of PERKINs (2019b). Depositories. The material examined is deposited in the following collections: 
MCZ Museum of Comparative Zoology, Harvard University, Cambridge, Massachusetts, USA (P. D. Perkins);

NHM Natural History Museum, London, UK (M. V. L. Barclay);

NMNH National Museum of Natural History, Smithsonian Institution, Washington, D.C., USA (C. J. Micheli).

Abbreviations for characters on male genitalia figures. The following abbreviations are used for male genitalia characters on the figures. More context concerning these and other Hydrochus genitalia characters are present in Perkins (2019b).

Aedeagus characters:

$a d b l$ aedeagus dorsal basal lobe;

$a d m$ aedeagus dorsal margin;

adtl aedeagus dorsal transition line (dorsal area where sclerotized and membranous parts of the aedeagus meet);

agw aedeagus greatest width;

alsm aedeagus lateral sclerotized margin;

alm aedeagus lateral margin; alw aedeagus least width;

avm aedeagus ventral margin;

avtl aedeagus ventral transition line (ventral area where sclerotized and membranous parts of the aedeagus meet).

Paramere characters:

pdmm paramere dorsal medial margin;

pdm paramere dorsal margin;

plsa paramere lateral subapical angle;

pvmm paramere ventral medial margin;

pwsa paramere weakly sclerotized area.

Other abbreviations used in descriptions. In addition to the above abbreviations, the following ones are used in species descriptions:

$\begin{array}{ll}\text { E } & \text { elytra; } \\ \text { HW } & \text { maximum width of head at eyes; } \\ \text { P } & \text { pronotum; } \\ \text { PA } & \text { width of anterior margin of pronotum; } \\ \text { PB } & \text { width of posterior margin of pronotum. }\end{array}$

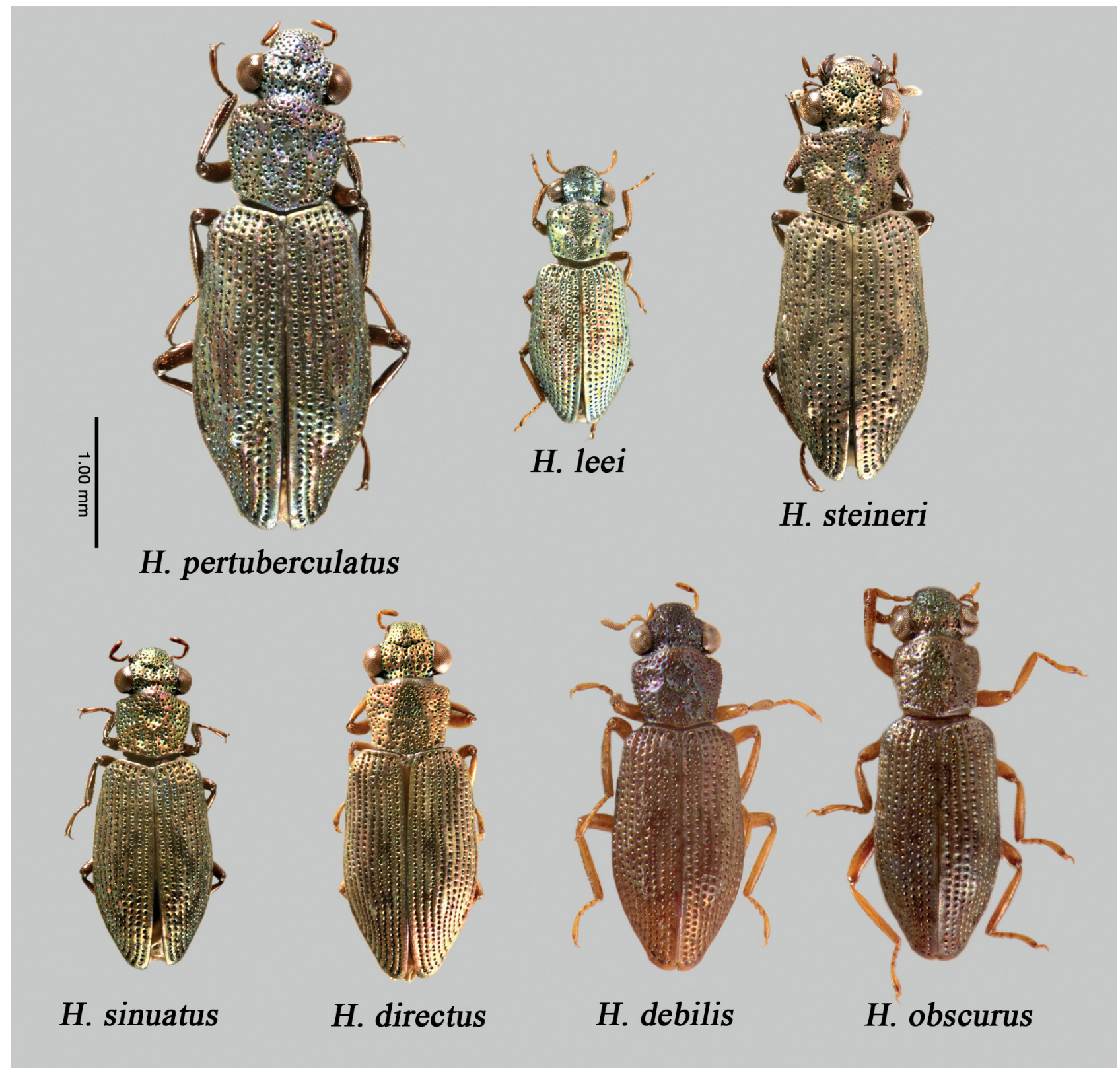

Fig. 1. Dorsal habitus of Guatemalan Hydrochus species. 


\section{Species (re)descriptions}

\section{Hydrochus debilis Sharp, 1882}

(Figs 1, 2, 8)

Hydrochus debilis Sharp, 1882: 89.

Type material examined. LeCtotype (hereby designated, Fig. 8): male (NHM): 'Hydrochus debilis Type D. S. Chontales. Nicaragua Janson // [male symbol] // LECTOTYPE [blue disc] // Chontales, Nicaragua. Janson. // B.C.A. Col. I. 2. Hydrochus debilis, Sharp. // HABITUS / GENIT. DIGITAL IMAGES captured 2020 P.D. Perkins // [red] LECTOTYPE Hydrochus debilis Sharp desig. P. D. Perkins'. Paralectotype: female (NHM): 'Hydrochus debilis Type D. S. Chontales. Nicaragua // [female symbol] // PARALECTOTYPE [blue disc] // Chontales, Nicaragua. Janson. // B.C.A. Col. I. 2. Hydrochus debilis, Sharp. // LECTOPARATYPE H. debilis by J. L. Hellman 75 // [yellow] PARALECTOTYPE Hydrochus debilis Sharp desig. P. D. Perkins'.

Additonal material examined (15 spec.). GUATEMALA: Izabal, $1 \mathrm{mi}$. N. Morales. Km 239 Atlantic Hwy, 16-18.viii.1965, leg. Paul J. Spangler (1: NMNH); 20 mi. SW Puerto Barrios, 16.viii.1965, leg. Paul J. Spangler (4: NMNH); 28 mi. SW Puerto Barrios, 16.viii.1965, leg. Paul J. Spangler (1: NMNH); Rio Dulce Fy., 2.vii.1974, leg. W. E. Steiner (9: NMNH).
Lectotype designation. The NHM kindly provided two syntypes of Hydrochus debilis, which are part of the Sharp Biologia Centrali-Americana types collection. The syntypes consist of one male and one female. I have selected the male to serve as lectotype and labeled it as such, and provide images of the habitus, male genitalia, and labels of that specimen (Figs 1,2,8). The other syntype has been labeled paralectotype. One additional specimen provided by the NHM as 'Possible type' is a different species, from Mexico. One of the syntypes bears a lectotype label, by J. L. Hellman, but this designation was never published. This label has been reversed and "unpub." written on the reverse side.

Differential diagnosis. Among Guatemalan species, H. debilis is recognized by the combination of moderate size (ca. 2.69-3.08 mm), the densely punctate pronotum with deep foveae, and the elytral sculpture, each elytron having four raised interstriae: $3^{\text {rd }}$ slightly raised over basal

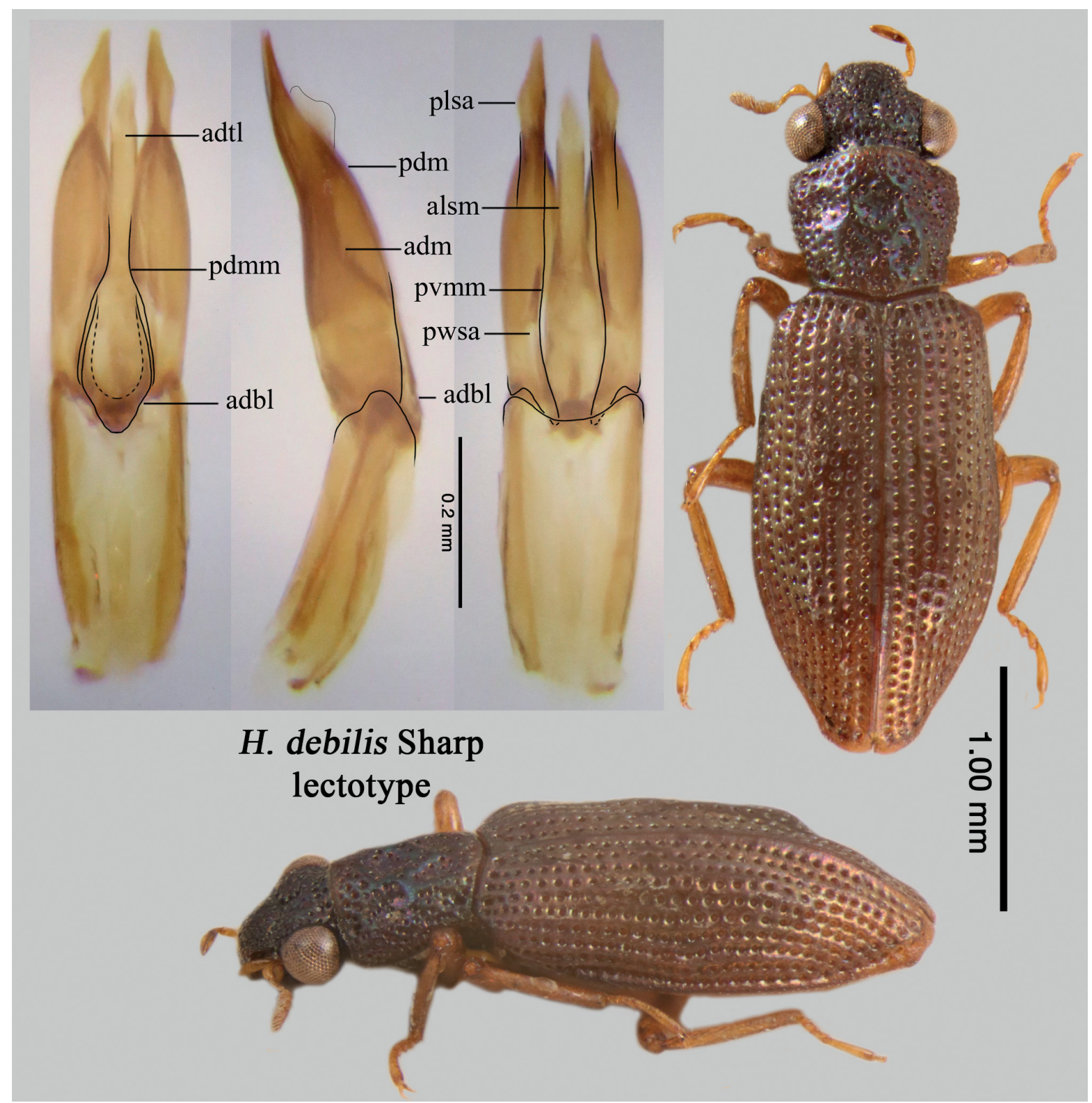

Fig. 2. Hydrochus debilis Sharp, 1882, habitus and male genitalia of lectotype. 
$1 / 4,4^{\text {th }}$ raised in area anterior to large callus of $5^{\text {th }}, 5^{\text {th }}$ raised from about anterior $1 / 4$ to midlength, and usual callus of $5^{\text {th }}$. The distinctive male genitalia (Fig. 2; described below) are also diagnostic.

Redescription. Habitus as illustrated (Fig. 2). Size (in $\mathrm{mm})$ : Lectotype: body (length to elytral apices / width) 2.88 / 1.04; head width 0.69 ; pronotum length / width 0.75 / 0.71; PA 0.67; PB 0.56; elytra length / width 1.85 / 1.04 . Body size moderate (ca. 2.69-3.08 mm in Guatemalan specimens). Dorsum dark grey to black, with very slight if any iridescence, elytra with black spots. Legs dark brown, with tibiofemoral joints slightly darker. Punctation on elytra ca. $2-4 \times$ that of pronotum. Elytra interstriae ca. $0.5-1.0 \times$ strial puncture diameter. Interstria $9^{\text {th }}$ more convex than others, overhanging $10^{\text {th }}$ interstria. Callus on $5^{\text {th }}$ in usual area, large, very strongly raised.

Pronotum length ca. equal width, widest at ca. anterior $1 / 3$, narrowed at base, sides sinuate, minutely denticulate; anterior margin slightly bisinuate; depressions deep, reliefs sharply raised, depressions and reliefs densely punctate.

Elytra with spaces between strial punctures narrow ridges to ca. $0.5 \times$ their diameter; $3^{\text {rd }}$ interstria slightly raised over basal fourth; $4^{\text {th }}$ interstria raised in area anterior to

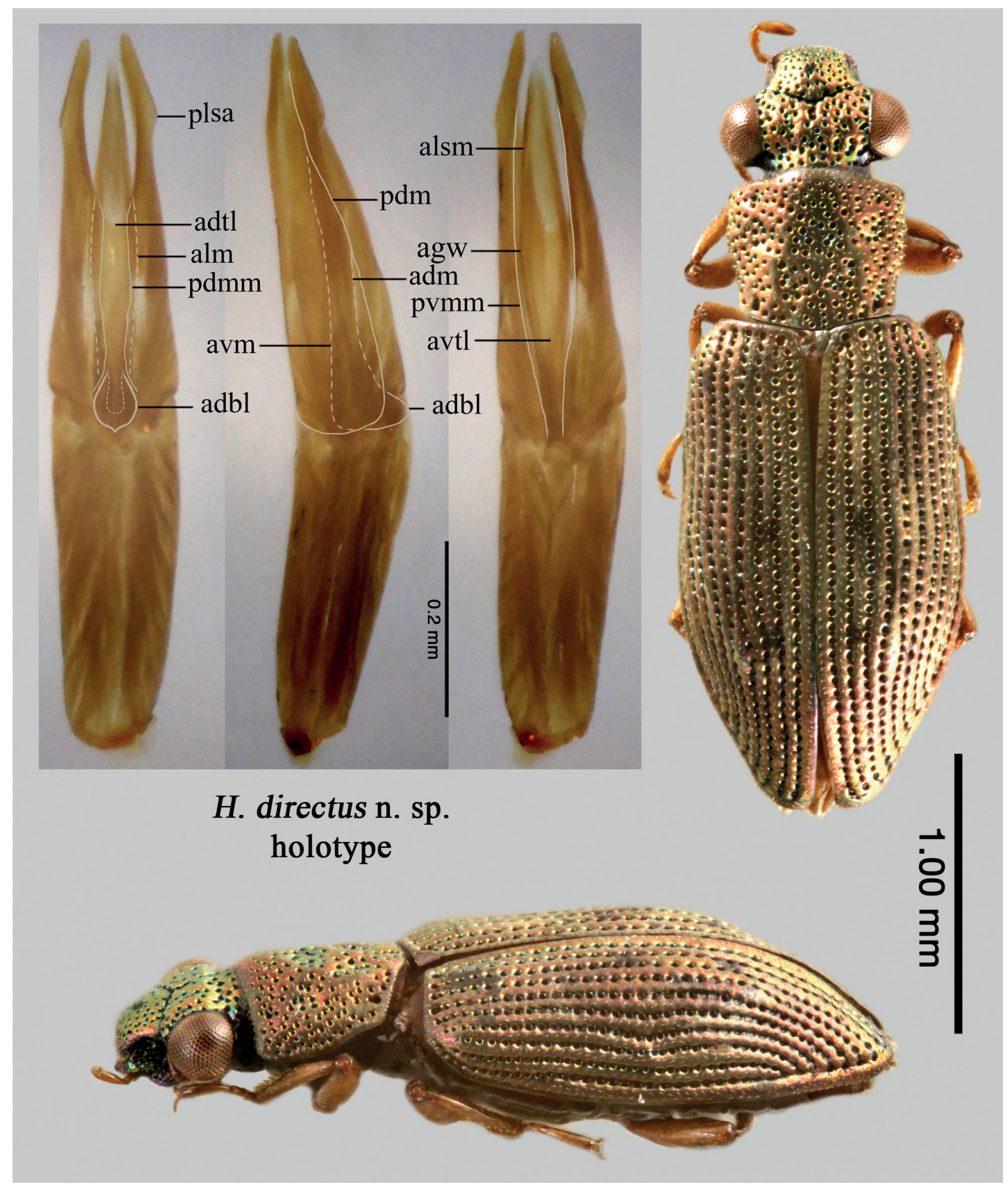

Fig. 3. Hydrochus directus sp. nov., habitus and male genitalia of holotype. 
callus of $5^{\text {th }} ; 5^{\text {th }}$ interstria raised from about anterior fourth to midlength, raised area separated from callus of $5^{\text {th }}$ by very slight depression; apices rather sharply conjointly rounded in dorsal view, in lateral view outer margin with moderate angulation.

Male genitalia (Fig. 2). General characters: paramere tips moderately large, extending beyond distal tip of aedeagus, sagittate, distal ends pointed, lateral margins between $p l s a$ and distal end slightly emarginate, medial margins of tips very slightly arcuate toward midline and well separated from lateral margins of aedeagus; parameres in dorsal/ventral views constricted at base of tips and dorsally with low ridge; parameres in dorsal/ventral views much wider at widest point than tips; parameres in lateral view wide, sinuate, and tapering to sharp tips; aedeagus greatest width at $a d b l$, shaft (portion of aedeagus distal to $a d b l$ ) in dorsal/ventral views very narrow, almost parallel-sided; aedeagus dorsal margin sinuate in lateral view; basal piece shorter than parameres, with rim of orifice sclerotized.

Dorsal surface: adtl located at about distal fifth of aedeagus; $p d m m$ very slightly narrowly overlapping alm at about midlength of aedeagus; $a d b l$ very large, much wider than paramere area lateral to $a d b l$, distinctively shaped.

Ventral surface: $p v m m$ overlapping alm at base; $p w s a$ near base.

\section{Hydrochus directus sp. nov. (Figs 1,3)}

Type material. Holotype: male (NMNH): 'GUATEMALA, 20 Mi. SW Puerto Barrios VIII-16-1965 Paul J. Spangler'. ParatyPes (13 spec.): GUATEMALA: same data as holotype (4 NMNH); '28mi. SW Puerto Barrios, VIII-16-1965, Paul J. Spangler' (1: NMNH); '15 Mi. W. Pijije, VIII-5-1965, P. J. Spangler' (1: NMNH); 'Peten, Tikal, 28 June 1974, W. E. Steiner' (7: NMNH).

Differential diagnosis. Among Guatemalan species, H. directus is recognized by the combination of moderate size (ca. 2.54-3.00 $\mathrm{mm}$ ), the densely punctate pronotum with the reliefs slightly less punctate than the depressions, and the male genitalia (Fig. 3; described below). This species has a generalized Hydrochus habitus; reliable determinations will require dissection of males.

Description. Habitus as illustrated in Fig. 3. Size (in mm): holotype: body (length to elytral apices / width) 2.76 / 1.02; head width 0.67 ; pronotum length / width 0.62 / 0.65; PA 0.62 ; PB 0.56; elytra length / width $1.73 / 1.02$. Body size moderate (ca. 2.54-3.00 mm). Dorsum grey, with moderately strong gold iridescence, elytra with black spots. Legs testaceous, with tibiofemoral joints slightly darker. Punctation on elytra ca. $2 \times$ that of pronotum. Elytra interstriae ca. $1.0-1.5 \times$ strial puncture diameter. Interstria $9^{\text {th }}$ more convex than others, overhanging $10^{\text {th }}$ interstria. Callus on usual area of $5^{\text {th }}$ interstria weakly raised, moderately long.

Pronotum length slightly less than width, widest at about anterior $1 / 3$, narrowed at base, sides sinuate, smooth; anterior margin bisinuate; depressions shallow, reliefs low, depressions more densely punctate than reliefs.

Elytra with spaces between strial punctures narrow ridges; apices rather sharply conjointly rounded in dorsal view, in lateral view outer margin with very slight angulation.

Male genitalia (Fig. 3). General characters: paramere tips elongate, slightly widened, distal ends pointed, lateral margins straight from $p l s a$ to distal tip, medial margins of tips emarginate and well separated from lateral margins of aedeagus, distal end of tips extending slightly beyond aedeagus, in lateral view tips narrow, pointed; aedeagus lanceolate in dorsal/ventral views, widest at ca. midlength, ca. same width as $a d b l$, from which point markedly tapering to sharp distal end, with narrowly sclerotized lateral margins; basal piece slightly shorter than parameres, tapering from distal end to orifice, with rim of orifice strongly sclerotized.

Dorsal surface: adtl located slightly distal to midlength of aedeagus; $p d m m$ narrowly overlapping alm over basal two-thirds then arcuate where paramere tips begin; $a d b l$ moderately large, ca. same width as greatest width of aedeagus shaft.

Ventral surface: $p v m m$ very slightly overlapping alm at base; avtl at about proximal fourth.

Etymology. Named in reference to the male genitalia, which have the paramere tips elongate, with straight lateral margins, and the aedeagus sharply pointed. Adjective.

\section{Hydrochus obscurus Sharp, 1882 \\ (Figs 1, 4, 8)}

Hydrochus obscurus Sharp, 1882: 90.

Hydrochus vanbergehenegouweni Makhan, 1992 (synonymized by OLIVA 1996)

Type material examined. LECTOTYPE (hereby designated): male (NHM): 'Hydrochus obscurus D. S. Paso Antonio. Guatemala. Champion [written on specimen card] // [male symbol] // LECTOTYPE [blue disc] // Paso Antonio, $400 \mathrm{ft}$. Champion. // B.C.A. Col. I. 2. Hydrochus obscurus Sharp. // HABITUS/GENIT. DIGITAL IMAGES captured 2020 P.D. Perkins // [red] LECTOTYPE Hydrochus obscurus Sharp desig. P. D. Perkins.' PARALECTOTYPES: 2 females (NHM): label data same as lectotype, except with blue paralectotype labels, and yellow labels: 'PARALECTOTYPE // Hydrochus obscurus Sharp // desig. P. D. Perkins'.

Additional material examined (26 spec.): GuATEMaLA: Izabal, $1 \mathrm{mi}$. N. Morales. Km 239 Atlantic Hwy, 16-18.viii.1965, leg. Paul J. Spangler (2 NMNH); 20 mi. SW Puerto Barrios, 16.viii.1965, leg. Paul J. Spangler (5 NMNH); 28 mi. SW Puerto Barrios, 16.viii.1965, leg. Paul J. Spangler (18: NMNH); Quirigua, 14.viii.1965, leg. P. J. Spangler (1: NMNH).

Lectotype designation. The NHM kindly provided three syntypes of Hydrochus obscurus, which are part of the Sharp Biologia Centrali-Americana types collection. The syntypes consist of one male and two females, all from Paso Antonio, Guatemala. I have selected the male to serve as lectotype and labeled it as such, and provide images of the habitus, male genitalia, and labels of that specimen (Figs 1, 4, 8). The other syntypes have been labeled paralectotypes. One of the syntypes bears a lectotype label by J. L. Hellman, but this designation was never published. This label has been reversed and 'unpub.' written on the reverse side.

Differential diagnosis. Among Guatemalan species, H. obscurus is recognized by the combination of moderate size (ca. 2.69-3.23 mm), the moderately low and relatively impunctate pronotal reliefs, and the male genitalia (Fig. 4). This species has a generalized Hydrochus habitus; 
reliable determinations will require dissection of males. The parameres are slightly spread in the lectotype; see $H$. obscurus genitalia figure in PERKINs (2019b) for non-spread condition.

Redescription. Habitus as illustrated in Fig. 4. Size of lectotype (in mm): body (length to elytral apices / width) 2.92 / 0.98; head width 0.69 ; pronotum length / width 0.63 / 0.67; PA 0.63; PB 0.58; elytra length / width 1.81 / 0.98. Body size moderate (ca. 2.69-3.23 mm in Guatemalan specimens). Dorsum grey, with slight to moderately strong iridescence, elytra with diffuse dark grey to black spots. Legs testaceous, with tibiofemoral joints darker. Punctation on elytra ca. $2-3 \times$ that of pronotum. Elytra interstriae ca. $1.0-1.5 \times$ strial puncture diameter. Interstria $9^{\text {th }}$ more convex than others, overhanging $10^{\text {th }}$ interstria. Callus on $5^{\text {th }}$ interstria in usual location, moderately raised, moderately elongate.
Pronotum length and width equal, or only very slightly wider than long, widest slightly behind anterior margin, narrowed at base, sides arcuate or very weakly sinuate, smooth; anterior margin slightly bisinuate; depressions deep to moderately deep, much more densely punctate than low reliefs between depressions, latter almost entirely impunctate.

Elytra with spaces between strial punctures ca. $0.5-1.0 \times$ their diameter; apices rather sharply conjointly rounded in dorsal view, in lateral view outer margin with slight angulation.

Ventral characters: Mentum coarsely punctate, with median fovea. Submentum with two foveae.

Male genitalia (Fig. 4). General characters: paramere tips in dorsal/ventral views very weakly sagittate, lateral margins between $p l s a$ and distal end very slightly emarginate, medial margins arcuate toward midline, in lateral

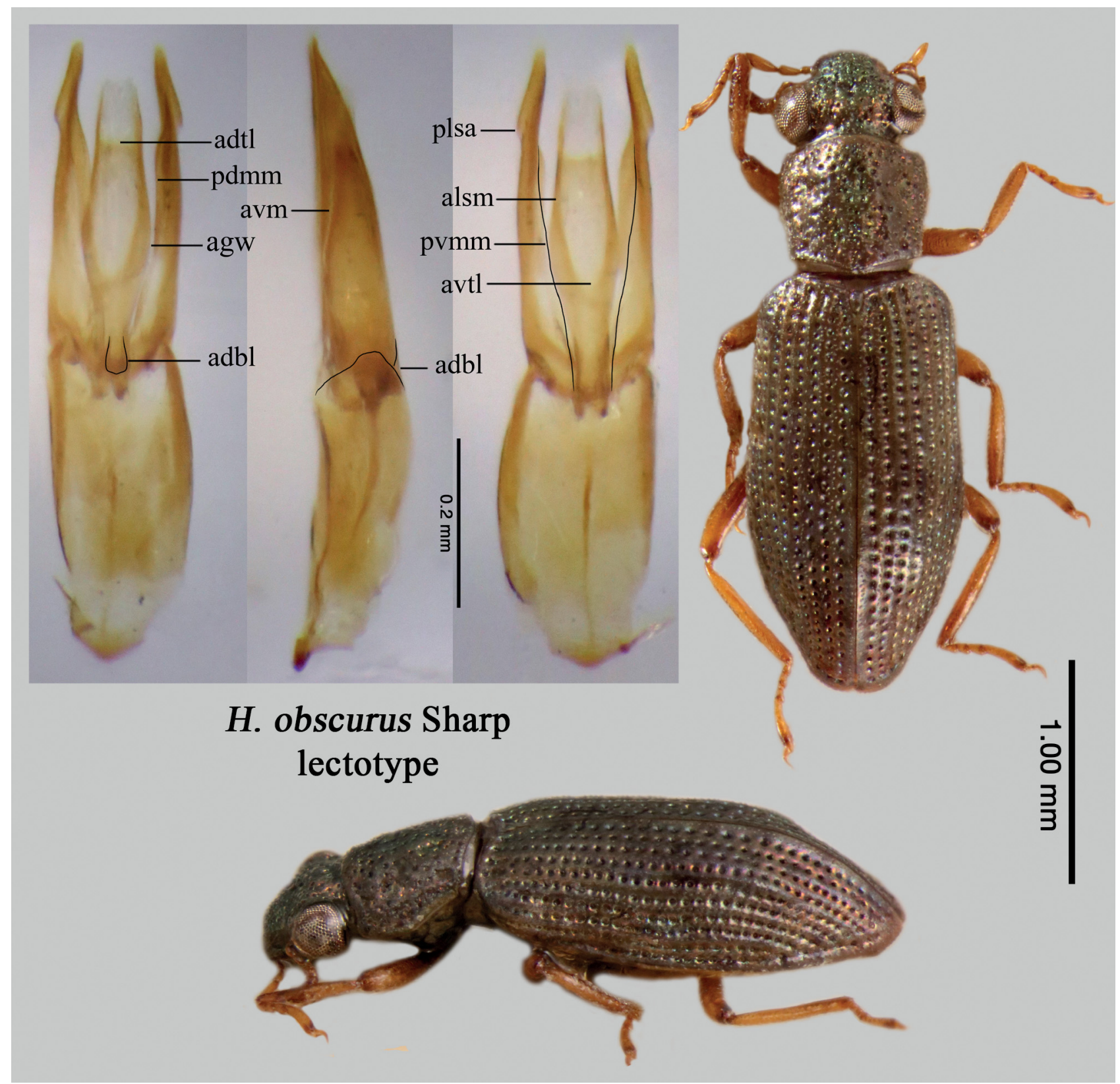

Fig. 4. Hydrochus obscurus Sharp, 1882, habitus and male genitalia of lectotype. 
view tips narrow and tapering; aedeagus basically lanceolate shaped, agw slightly before midlength; basal piece slightly shorter than parameres, with orifice sclerotized rim produced in small projection on apicoventral margin.

Dorsal surface: adtl at about distal third; $a d b l$ small; pdmm overlapping alm basally.

Ventral surface: avtl at about proximal third; $p v m m$ closely approximating aedeagus lateral margins.

Remarks. I have examined the holotype of Hydrochus vanbergehenegouweni from Venezuela, including the male genitalia. I concur with OLIVA (1996) that Hydrochus vanbergehenegouweni is conspecific with Hydrochus obscurus.

\section{Hydrochus pertuberculatus sp. nov. \\ (Figs 1, 5)}

Type material. Holotype: male (NMNH): 'GUATEMALA, $20 \mathrm{Mi}$. SW Puerto Barrios VIII-16-1965 Paul J. Spangler’. Paratype: 1 male (NMNH): same data as holotype.

Differential diagnosis. The largest of known Guatemalan species (body length $3.56-3.85 \mathrm{~mm}$ ), recognized by the combination of the body size, the densely punctate pronotum with deep foveae, the elytral sculpture, having a very large callus on the $5^{\text {th }}$ interstria, the $3^{\text {rd }}$ interstria slightly raised over the basal $1 / 4$, and the $4^{\text {th }}$ interstria raised in the area anterior to $5^{\text {th }}$ callus, and the male genitalia (Fig. 5; described below).

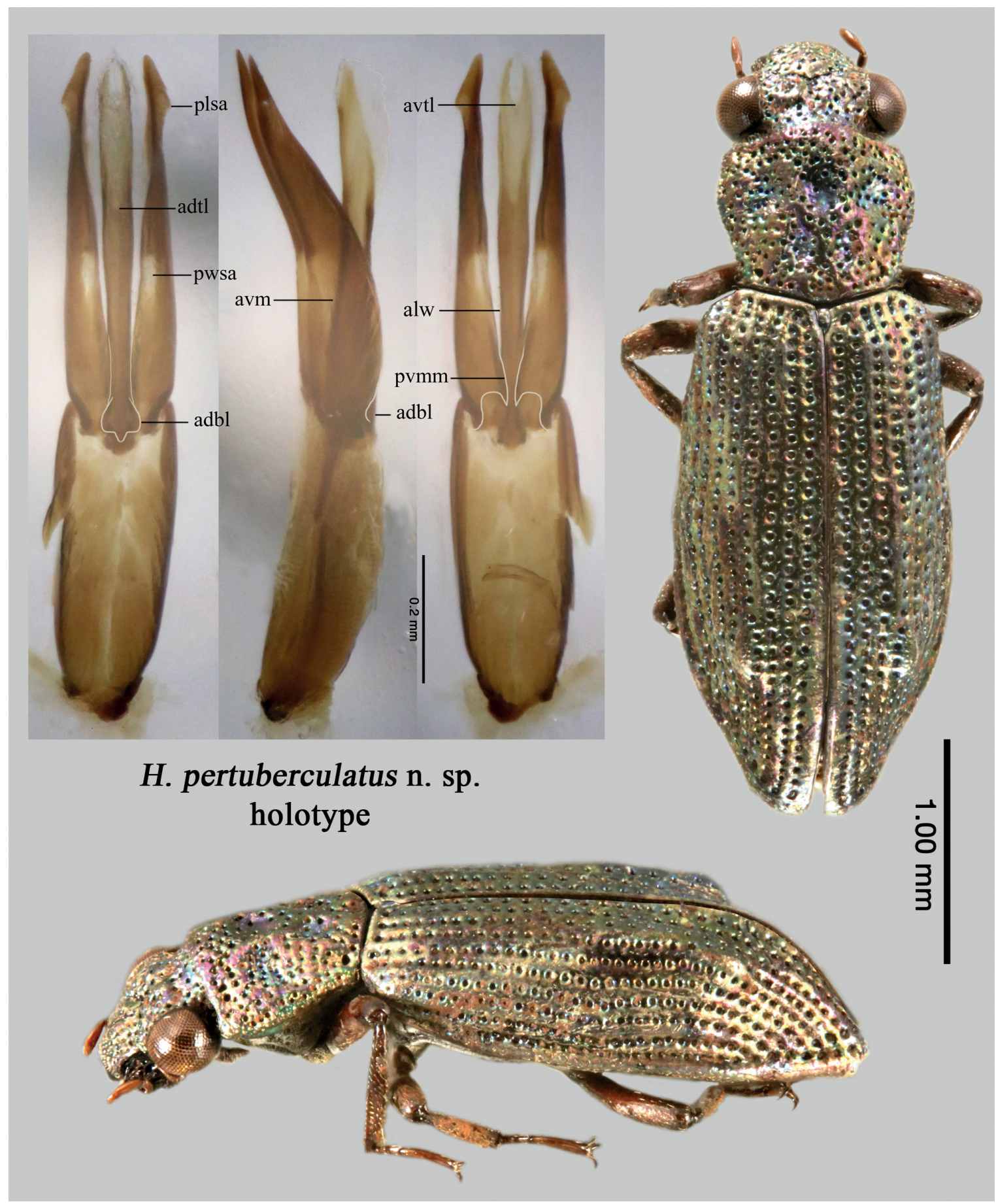

Fig. 5. Hydrochus pertuberculatus sp. nov., habitus and male genitalia of holotype. 
Description. Habitus as illustrated in Fig. 5. Size (in mm): holotype: body (length to elytral apices / width) 3.56 / 1.28; head width 0.86 ; pronotum length / width 0.84 / 0.91; PA 79; PB 0.77; elytra 2.33 / 1.28. Body size moderate (ca. $3.56-3.85 \mathrm{~mm}$ ). Dorsum black, with very slight, if any, iridescence, elytra without black spots. Legs dark brown, with tibiofemoral joints slightly darker. Punctation on elytra ca. $2-4 \times$ that of pronotum. Elytra interstriae ca. $0.5-1.5 \times$ strial puncture diameter. Interstria $9^{\text {th }}$ more convex than others, overhanging $10^{\text {th }}$ interstria. Usual area of callus on $5^{\text {th }}$ large, very strongly raised.

Pronotum length slightly less than width, widest at ca. anterior third, narrowed at base, sides sinuate, minutely denticulate; anterior margin bisinuate; depressions, especi- ally anteromedian, deep, reliefs sharply raised, depressions and reliefs densely punctate.

Elytra with spaces between strial punctures ca. 0.5-1.0× their diameter; $3^{\text {rd }}$ interstria slightly raised over basal fourth; $4^{\text {th }}$ interstria raised in area anterior to large callus of $5^{\text {th; }}$; posterior declivity abrupt and suture raised in this area, apices rather sharply conjointly rounded in dorsal view, in lateral view with submarginal row of large punctures, bordered above by low ridge, outer margin with strong angulation.

Male genitalia (Fig. 5). General characters: genitalia long and narrow; paramere tips small, sagittate, distal ends pointed, lateral margins between distal end and $\mathrm{plsa}$ straight, not emarginate, medial margins of tips slightly

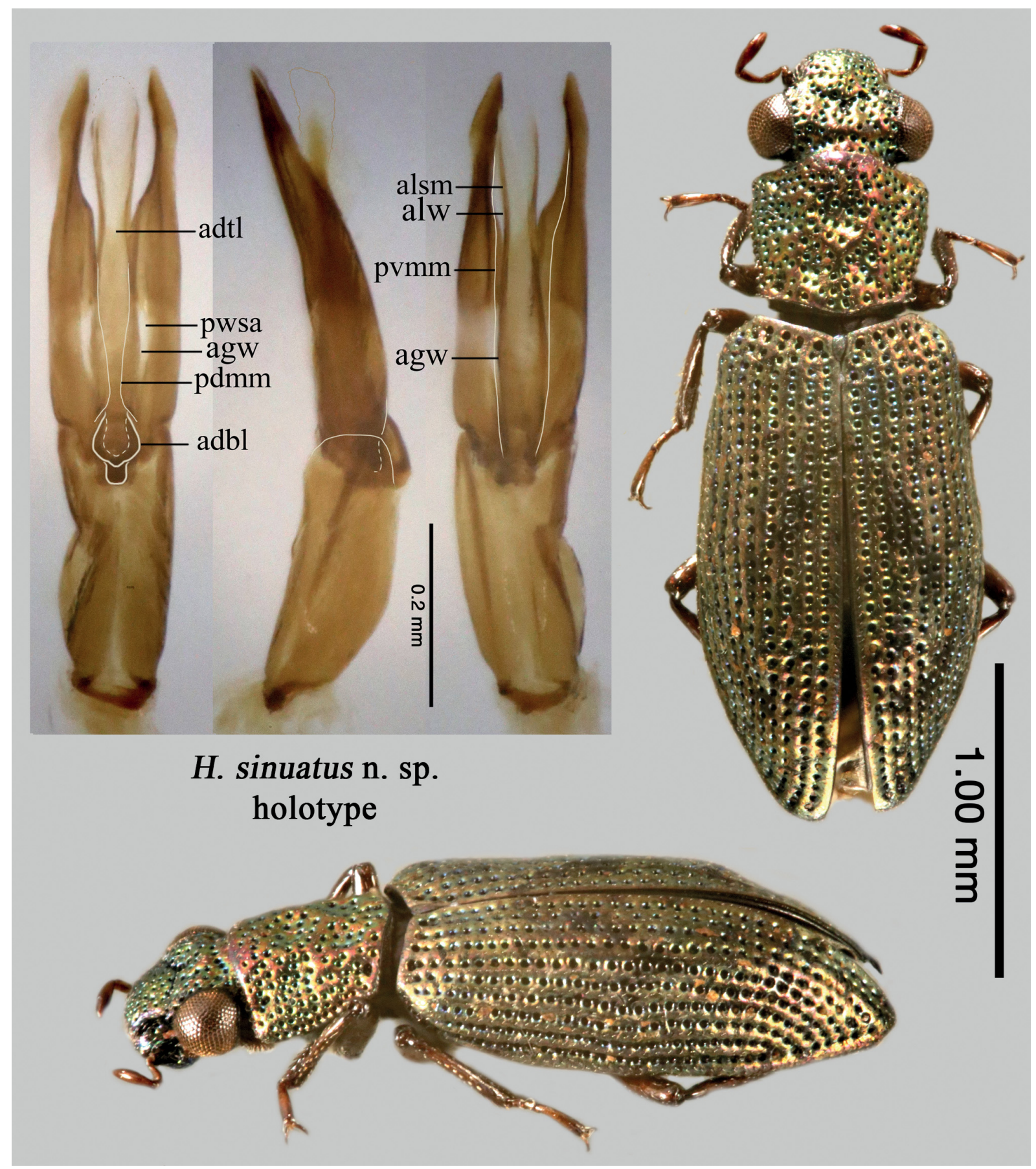

Fig. 6. Hydrochus sinuatus sp. nov., habitus and male genitalia of holotype. 
emarginate and well separated from lateral margins of aedeagus, distal end of tips not extending beyond aedeagus, in lateral view tips narrow, sharply pointed; aedeagus very narrow in both dorsal/ventral and lateral views, widest at $a d b l$, narrowest at ca. proximal third, with narrowly sclerotized lateral margins; basal piece shorter than parameres, with rim of orifice strongly sclerotized.

Dorsal surface: adtl located slightly distal to midlength of aedeagus; $p d m m$ very slightly narrowly overlapping alm at base; $a d b l$ large, distinctively shaped.

Ventral surface: avtl subapical, U-shaped; pvmm overlapping alm at base.

Etymology. Named in reference to the very large tubercles on the $5^{\text {th }}$ elytral interstriae. Adjective.

\section{Hydrochus sinuatus sp. nov. \\ (Figs 1,6)}

Type material. HoLOTYPe: male (NMNH): 'GUATEMALA, 20 Mi. SW Puerto Barrios VIII-16-1965 Paul J. Spangler’.

Differential diagnosis. Among Guatemalan species, $\mathrm{H}$. sinuatus is recognized by the combination of moderately small size (ca. $2.39 \mathrm{~mm}$ ), the densely coarsely punctate pronotum, and the male genitalia (Fig. 6; described below). This species has a generalized Hydrochus habitus; reliable determinations will require dissection of males.

Description. Habitus as in Fig. 6. Size (in mm): holotype: body (length to elytral apices / width) 2.39 / 0.89; head width 0.58 ; pronotum length / width 0.53 / 0.55; PA 0.53 ; PB 0.48; elytra $1.52 / 0.89$. Body size moderate.

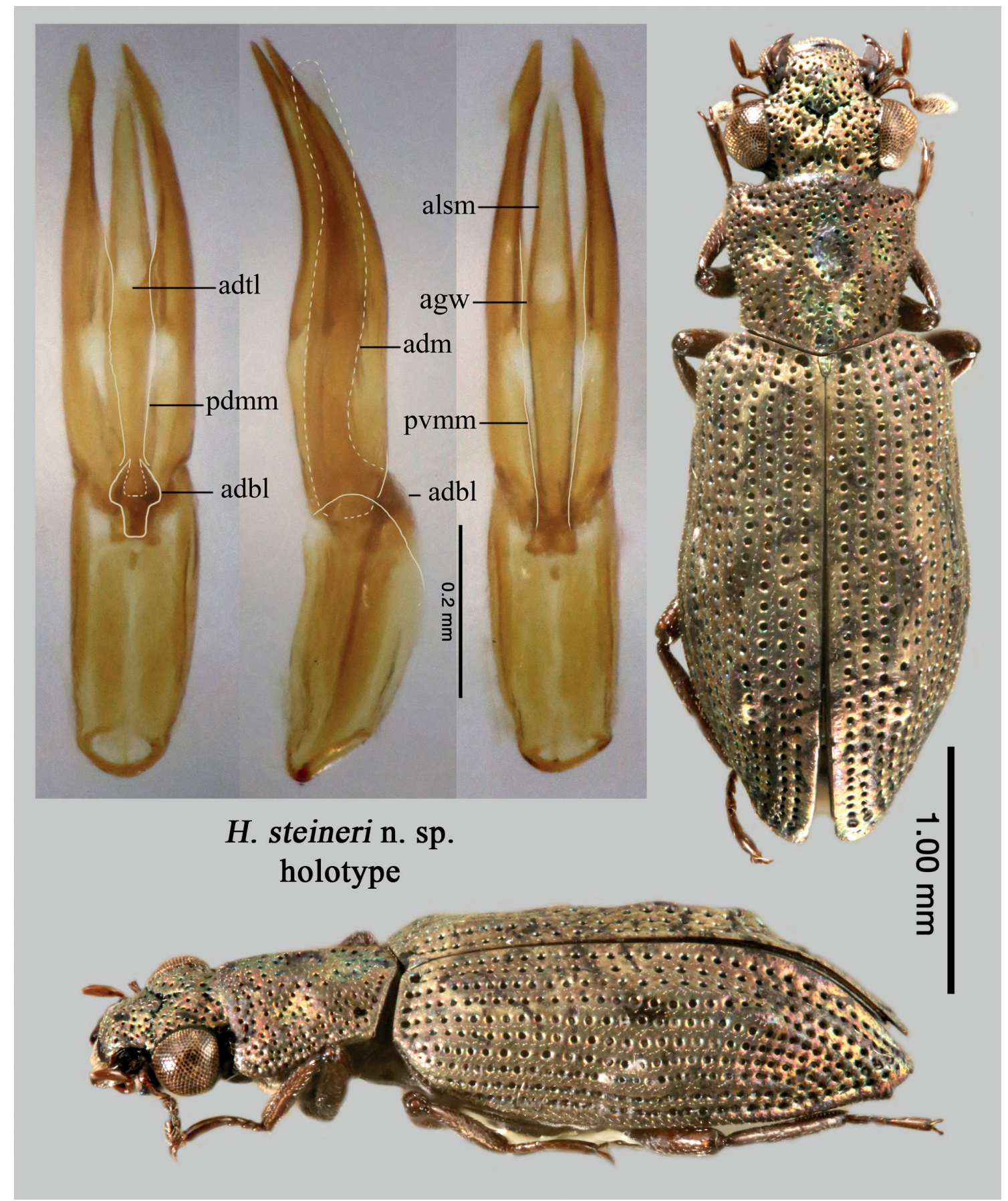

Fig. 7. Hydrochus steineri sp. nov., habitus and male genitalia of holotype. 
Dorsum black, with moderately strong iridescence, elytra with non-iridescent black spots. Legs dark brown, with tibiofemoral joints slightly darker. Punctation on elytra ca. $2-4 \times$ that of pronotum. Elytra interstriae ca. $0.5-1.0 \times$ strial puncture diameter. Interstria $9^{\text {th }}$ more convex than others, overhanging $10^{\text {th }}$ interstria. Callus on usual area of $5^{\text {th }}$ interstria small, weakly raised.

Pronotum length slightly less than width, widest just behind anterior angles, narrowed at base, sides very slightly sinuate, minutely denticulate; anterior margin bisinuate; depressions, especially anteromedian, deep, reliefs sharply raised, depressions more densely punctate than reliefs.

Elytra with spaces between strial punctures ca. $0.5-1.0 \times$ their diameter; $3^{\text {rd }}$ interseries slightly raised over basal fourth; $4^{\text {th }}$ interseries raised in area anterior to callus of $5^{\text {th }}$; apices rather sharply conjointly rounded in dorsal view, in lateral view with submarginal row of large punctures, bordered above by low ridge, outer margin with strong angulation.

Male genitalia (Fig. 6). General characters: paramere tips slightly widened, distal ends pointed, lateral margins arcuate, medial margins of tips emarginate and well separated from lateral margins of aedeagus, distal end of tips extending very slightly beyond aedeagus, in lateral view tips narrow, sharply pointed; $p w s a$ distinctive; aedeagus moderately narrow in both dorsal/ventral and lateral views, in dorsal/ventral views margins sinuate, distinctly narrowed slightly past midlength in dorsal/ventral views, with narrowly sclerotized lateral margins; basal piece shorter than parameres, with rim of orifice strongly sclerotized.

Dorsal surface: adtl located slightly distal to midlength; $\mathrm{pdmm}$ narrowly overlapping alm over basal two-thirds, then markedly arcuate where paramere tips begin; $a d b l$ large, distinctively shaped.

Ventral surface: pvmm very slightly overlapping alm at base.

Etymology. Named in reference to the shape of the parameres and aedeagus, which have sinuate lateral margins. Adjective.

\section{Hydrochus steineri sp. nov. \\ (Figs 1,7)}

Type material. HoLOTYPE: male (NMNH): 'GUATEMALA: Peten, Tikal, 28 June 1974 , W. E. Steiner'

Differential diagnosis. Among Guatemalan species, recognized by the combination of moderate size (ca. 3.29 $\mathrm{mm}$ ), the densely punctate pronotum with deep foveae, the elytra with strial punctures smaller than interstriae, and the male genitalia (Fig. 7; described below). This species has a generalized Hydrochus habitus; reliable determinations will require dissection of males.

Description. Habitus as in Fig. 7. Size (in mm): holotype: body (length to elytral apices / width) 3.29 / 1.18; head width 0.80; pronotum length / width 0.73 / 0.78; PA 0.76; PB 0.63; elytra 1.98/1.18. Body size moderate. Dorsum black, with moderately strong iridescence, elytra with non-iridescent black spots. Legs dark brown. Punctation on elytra ca. $2-4 \times$ that of pronotum. Elytra interstriae ca. $1.0-1.5 \times$ strial puncture diameter. Interstria $9^{\text {th }}$ more convex than others, overhanging $10^{\text {th }}$ interstria. Callus on usual area of $5^{\text {th }}$ interstria large, strongly raised.

Pronotum length slightly less than width, widest just behind anterior angles, narrowed at base, sides sinuate, smooth; anterior margin bisinuate; depressions deep, reliefs moderately sharply raised, depressions more densely punctate than reliefs.

Elytra with spaces between strial punctures ca. $1 \times$ their diameter; $4^{\text {th }}$ interseries raised in area anterior to callus of $5^{\text {th}}$; apices rather sharply conjointly rounded in dorsal view, in lateral view outer margin with weak angulation.

Male genitalia (Fig. 7). General characters: paramere tips slightly widened, distal ends pointed, lateral margins arcuate, medial margins of tips emarginate between angulation and distal end, and well separated from lateral margins of aedeagus, distal end of tips extending slightly beyond aedeagus, in lateral view tips narrow, sharply pointed; parameres in lateral view markedly sinuate; parameres with distinct $p w s a$ at ca. proximal third; aedeagus moderately

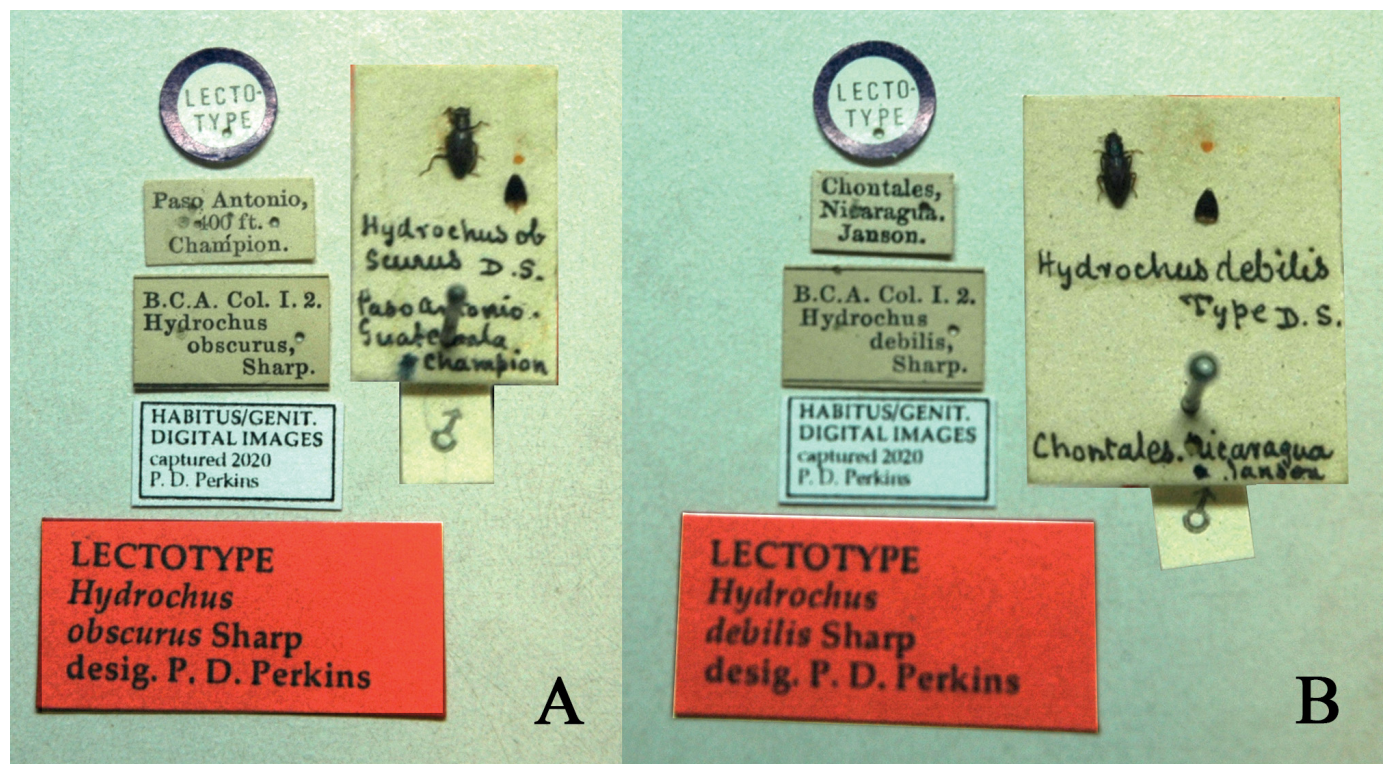

Fig. 8 Hydrochus lectotype labels. A - H. obscurus Sharp, 1882; B - H. debilis Sharp, 1882. 
narrow in both dorsal/ventral and lateral views, $a g w$ at ca. mid-length, from which point markedly tapering to sharp distal end, with narrowly sclerotized lateral margins; basal piece much shorter than parameres, slightly wider in lateral than dorsal/ventral views, with rim of orifice moderately sclerotized.

Dorsal surface: adtl located slightly distal to midlength of aedeagus; $p d m m$ narrowly overlapping alm at base; $a d b l$ large.

Ventral surface: $p v m m$ very slightly overlapping alm at base.

Etymology. Named in honor of Warren E. Steiner, longtime friend and colleague, who has collected many new species of Neotropical Hydrochus, including the only known specimen of this species.

\section{Acknowledgments}

I am grateful to Charyn Micheli for assistance with the Hydrochus specimens deposited in the NMNH. Special thanks to the following curators for providing loans of crucial type specimens, without which this study would not have been possible: Max Barclay (NHM, London), Hans Huijbregts (RMNH, Leiden) Manfred Jäch (NMW, Vienna), Bernd Jaeger (ZMHB, Berlin), Pol Limbourg (RBINS, Brussels), and György Makranczy (HNHM, Budapest).

\section{References}

JÄCH M. A. 2006: Taxonomy and nomenclature threatened by D Makhan. Koleopterologische Rundschau 76: 360.

MAKHAN D. 1992: Twelve new Hydrochus-species from South America. Phegea 202: 95-103.

MAKHAN D. 1993: Nine new Hydrochus species from South and Central America. Annales Historico-Naturales Musei Nationalis Hungarici 85: 65-70.

MAKHAN D. 1994: Thirty-five new Hydrochus species from the Old and the New World (Coleoptera: Hydrophilidae). Annales Historico -Naturales Musei Nationalis Hungarici 86: 29-42.

MAKHAN D. 1995a: Descriptions of ten new species of Hydrochus from different parts of the World (Coleoptera: Hydrochidae). Phegea 23: $187-193$.

MAKHAN D. 1995b: Descriptions of six new species of Hydrochus from South and North America (Coleoptera: Hydrochidae). Zoological Studies 34: 18-20.
MAKHAN D. 1996: Descriptions of three new species of Hydrochus (Coleoptera: Hydrochidae). Phegea 24: 183-185.

MAKHAN D. 1998: Three new genera and two new species of Hydrochidae from different parts of the World (Coleoptera). Annales Historico-Naturales Musei Nationalis Hungarici 90: 139-150.

MAKHAN D. 2000: Hydrochidae Coleoptera: from North America with description of Hydrochus pajnii sp. nov. and Hydrochus yadavi sp. nov. Pp 51-53. In: SOBTI R. C. \& YADAV J. S. (eds) Some aspects on the insight of insect biology. Narendra Publishing House, Delhi, India, $311 \mathrm{pp}$.

MAKHAN D. 2001: A new genus, Soesilius, and a new species of Hydrochidae (Coleoptera) from America. Russian Entomological Journal 10: 389-393.

MAKHAN D. 2004a: Hydrochidae of the world, Dryopidae and Hydrophilidae (Coleoptera). Calodema 2:11-26.

MAKHAN D. 2004b: Two new Hydrochidae (Coleoptera) species from the world. Acta Biologica Universitatis Daugavpiliensis 4: 107-109.

MAKHAN D. 2005: Hydrochus brianbrowni sp. nov. (Coleoptera: Hydrochidae), a new American species. Baltic Journal of Coleopterology 5: 63-65.

OLIVAA. 1992: The species of Hydrochus Coleoptera; Hydrophiloidea; Hydrochidae: described from South America. Bulletin et Annales de la Société Royale Belge d'Entomologie 128: 87-104.

OLIVA A. 1996: The genus Hydrochus Leach (Coleoptera: Hydrophiloidea: Hydrochidae) in South America, with special reference to Argentina. Bulletin et Annales de la Société Royale Belge d'Entomologie 132: 301-341.

OLIVA A. 2000: Hydrochus synonymies. Latissimus 12: 14.

PERKINS P. D. 2019a: Type designations for Neotropical water beetles in the genus Hydrochus Leach, 1817 (Coleoptera: Hydrochidae). Zootaxa 4701 (2): 149-167.

PERKINS P. D. 2019b: Taxonomy of Venezuelan water beetles in the genus Hydrochus Leach, 1817, and an analysis of male genitalia morphology (Coleoptera: Hydrochidae). Zootaxa 4708 (1): 1-59.

SHARP D. 1882: Insecta. Coleoptera. Vol. 1, part 2 (Haliplidae, Dytiscidae, Gyrinidae, Hydrophilidae, Heteroceridae, Parnidae, Georissidae, Cyathoceridae, Staphylinidae). Pp 1-144. In: GODMAN F. D. \& SALVIN O.: Biologia Centrali-Americana. Volume 16. Taylor and Francis, London, $\mathrm{xv}+824 \mathrm{pp}$.

SHORT A. E. Z. \& HEBAUER F. 2006: World catalogue of Hydrophiloidea - additions and corrections, 1 (1999-2005) (Coleoptera). Koleopterologische Rundschau 76: 315-359.

WORTHINGTON R. J., HELLMAN J. L. \& LAGO P. K. 2016: Hydrochidae (Coleoptera) of Mississippi. Transactions of the American Entomological Society 142: 167-213. 
